Rev. Elev. Méd. vét. Pays trop., 1974, 27 (1) : 57-59

\title{
Persistance de Salmonella abortus ovis dans le sol
}

\author{
par H. TADJEBAKHCHE (*) et A. A. NAZARI $\left(^{*}\right)$
}

\begin{abstract}
RESUME
Les auteurs ont ensemencé des parcelles de terre avec une suspension de bactéries de forme $* S *$ contenant $23 \times 10^{9} \mathrm{germes} / \mathrm{ml}$. Cette souche a pu être isolée jusqu'au 13 e jour puis seules des formes \& $\mathbf{R}$ » ont pu être identifiées, qui ont cependant fait avorter deux brebis en fin de gestation. Trente-neuf jours après l'avortement, $S$. abortus ovis sous sa forme « $S$ » a pu être isolée dans les fèces de l'une d'entre elles. Des anticorps spécifiques ont pu être mis en évidence.
\end{abstract}

\section{INTRODUCTION}

Devant l'extension considérable prise ces dernières années dans le monde et plus particulièrement en Iran par la salmonellose ovine à $S$. abortus ovis, il nous a paru indiqué et logique à la suite de nos précédents travaux sur la gestation de la brebis et chez d'autres animaux domestiques $(3,7,8)$ d'étudier le comportement de ce germe dans le sol, notamment en ce qui concerne sa survie.

\section{MATERIEL ET METHODES}

\section{Le sol}

Un terrain de $9 \mathrm{~m}^{2}$, de $3 \times 3 \mathrm{~m}$, préalablement reconnu comme absolument indemne de toute contamination à base de $S$. abortus ovis a été divisé en trois parcelles d'égales dimensions. La première de ces trois parcelles est restée sous sa forme de terre cultivable ordinaire, la deuxième a été constituée de terre mélangée à du sable et la troisième de terre cultivable enrichie de fumier de ferme, dans les proportions localement classiques, soit $6 \mathrm{~kg}$ pour $3 \mathrm{~m}^{2}$.

$\left({ }^{*}\right)$ Chaire de Microbiologie, Maladies contagieuses, Faculté vétérinaire, B.P. 3262, Téhéran, Iran.

\section{Les souches microbiennes}

Trois souches $(\mathrm{N}, 212,268)$ isolées à l'occasion de précédentes recherches et cultivées sur bouillon «Brain-Heart » ont été mélangées pour donner une suspension finale contenant $23 \times 10^{9}$ germes $/ \mathrm{ml}$.

Cette suspension a été répandue sur les trois parcelles de façon aussi égale que possible. Puis de la terre ainsi ensemencée a été recueillie, mise en pots qui ont été complètement enterrés à même le sol.

\section{Prélèvements}

Leur rythme a été le suivant :

Pour la terre : une fois par jour au cours des quinze premiers jours, ensuite deux fois par semaine jusqu'à la fin de l'expérience.

Pour les pots : le $95^{\circ}$ jour, un prélèvement a été fait dans un premier pot qui a aussitôt été à nouveau enterré, et prélèvement ultérieur au $152^{\mathrm{e}}$ jour.

Le même type de prélèvement a été effectué dans un deuxième pot 162 jours après son ensemencement.

\section{Cultures et identifications}

Les techniques utilisées ont été identiques à 
celles déjà décrites dans nos précédents articles $(3,4)$.

\section{Les animaux}

Ce sont des souris (une centaine au total), qui ont été utilisées tant pour confirmer le diagnostic que pour observer d'éventuelles transformations des souches « $\mathrm{R} \gg$ ensemencées en souches « $S$ ».

Chez ces souris, nous avons pu déclencher la maladie par les différentes voies d'inoculation, y compris la voie buccale et la voie pulmonaire.

Deux brebis à leur dernier mois de gestation, préalablement reconnues parfaitement indemnes (examens bactériologiques et tests sérologiques avec l'antigène de $S$. abortus ovis: 0 : $\mathrm{B} ; \mathrm{H}: \mathrm{c} ; \mathrm{H}: 6$ ) ont été respectivement infectées avec les germes isolés les $152^{\mathrm{e}}$ et $162^{\mathrm{e}}$ jours de l'expérience.

\section{RESULTATS}

Du début au treizième jour de l'observation, $S$. abortus ovis a pu être isolé de la terre sous sa forme « $S »$. Par la suite, seules des formes « $R \otimes$ ont pu être mises en évidence dans le sol et dans les pots aux 95, 152, 162 jours. Les essais pour mettre en évidence les formes « $S$ * tant par culture sur milieux divers que par inoculation à des souris ont été négatifs alors que les sujets mouraient en 48 heures.

Une des deux brebis gestantes, infectée à l'aide du germe isolé le $152^{\mathrm{e}}$ jour, a avorté 24 heures après l'injection intraveineuse et est morte peu après. Son agneau, après avoir survécu 24 heures a succombé après avoir présenté des signes de septicémic. Les prélèvements, effectués sur les différents organes du fœtus et de la mère, ont permis d'identifier $S$. abortus ovis sous sa forme « Rough ». L'autre brebis ayant reçu le germe isolé le $162^{\circ}$ jour a seulement avorté cinq jours après l'inoculation. Nous avons pu mettre en évidence dans les différents organes de son fotus le germe sous sa forme « R 》. Cependant, $S$. abortus ovis sous sa forme « $S$ » a pu être retrouvée dans les fèces de cette brebis le $39^{\mathrm{e}}$ jour après l'avortement.

Les séro-agglutinations effectuées sur cette brebis ont donné les résultats indiqués au tableau $\mathbf{n}^{\circ} \mathbf{I}$.

\section{DISCUSSION ET CONCLUSION}

Durant près de deux semaines, $S$. abortus ovis est restée sous forme « $\mathrm{S}$ 》 dans les différents sols. Passé ce délai, nous n'avons pu retrouver que des formes \& $R$ » et ceci pendant au moins 6 mois. Ces souches $« R \otimes$ correspondent cependant bien à $S$. abortus ovis puisque, chez la $2^{\text {e }}$ brebis avortée, qui auparavant ne l'hébergeait pas, nous avons pu l'isoler dans les fèces sous sa forme $\ll S$ » au $39^{\mathrm{e}}$ jour. En effet, en ce qui la concerne, les taux d'agglutination $\mathrm{O}: \mathrm{B}$ et $\mathrm{H}: \mathrm{c}$ rencontrés avant l'infestation étaient inférieurs aux seuils de positivité communément admis $(4,6)$. De plus, ceux-ci n'étant pas liés à l'existence d'agglutinines $H: 6$, ne présentaient pas un caractère de spécificité vis-à-vis de ce germe.

Cependant, 6 et 46 jours après l'inoculation ces taux $0: \mathbf{B} ; \mathrm{H}: \mathrm{c} ; \mathrm{H}: 6$ étaient très élevés et restaient supérieurs aux seuils de positivité.

On peut conclure à une survie relativement longue de $S$. abortus bovis. Pourtant, ce germe se conserverait alors sous la forme $《 R$, tout en restant pathogène pour la brebis. On pourrait penser ici à un phénomène de transformation de la souche « $R$ » en souche « $S$ » après ingestion par l'animal puisque seule cette dernière forme est susceptible de provoquer la maladie et de se retrouver dans les fèces des individus, après avortement.

\section{Remerciements}

Nous tenons à remercier M. le Professeur SHIMI, et M. GILLET pour leur excellente collaboration.

TABLEAU $\mathrm{N}^{*} \mathrm{I}$

Régultats des séroagglutinations sur 1a deuxième brebis

\begin{tabular}{|l|l|l|l|}
\hline Dates des prélèvements & O: B & H : c & H : 6 \\
\hline Avant 1'infestation & $1 / 20$ & $1 / 40$ & - \\
\hline 6 jours après 1'infestation & $1 / 5120$ & $1 / 20480$ & $1 / 1280$ \\
\hline 46 jours après 1'infestation & $1 / 40$ & $1 / 640$ & $1 / 320$ \\
\hline
\end{tabular}




\section{SUMMARY}

\section{Persistence of Salmonella abortus ovis in the soil}

In this experience, the authors have contaminated the soil with a suspension of Salmonella abortus ovis and were able to isolate daily until 13 days the " $S$ * form colonies of this bacteria. After this period only the " $\mathbf{R}$ " form of this Salmonella was isolated from the contaminated soil, but with these \& $\mathbf{R}$ » strains they were able to produce abortion in two ewes in the late of their pregnancy. 36 days after abortion $S$. abortus ovis was isolated from the feces of one of these ewes and the " $S$ » colonies reappeared, they were also able to show the specific antibodies.

\section{RESUMEN}

\section{La persistencia de Salmonella abortus ovis en el suelo}

Los autores sembraron parcelas de tierra con una suspensión de bacterias de forma « $\mathrm{S}$ » conteniendo $23 \times 10^{9}$ germenes $/ \mathrm{ml}$. Se pudo aislar esta cepa hasta el dia trece y luego identificar sólo formas \& $R$ * que sin embargo provocaron el aborto de dos ovejas al fin de la gestacion. Treinta y nueve días después del aborto, se pudo aislar $S$. abortus ovis bajo su forma « $S$ » en las heces de una de ellas. Se pusieron en evidencia anticuerpos especificos.

\section{BIBLIOGRAPHIE}

1. DELAGE (B.). Survie des Salmonelles dans la terre. Arch. Inst, Pasteur, Maroc, 1961, 6 : 139-142.

2. JACK (E. J.). $S$. abortus ovis: an atypical Salmonella. Vet. Rec., 1968, $82: 558-561$.

3. TADJEBAKHCHE (H.), DESLIENS (M.) et HEDJAZI (M.). Etude bactériologique d'enzootie d'avortements causés par Salmonella abortus ovis en Iran. Rev. Méd. vét., 1971, 122 : 618-621.

4. TADJEBAKHCHE (H.), DESLIENS (M.) et HEDJAZI (M.). Etude sérologique d'une enzootie d'avortements à Salmonella abortus ovis en Iran. Rec. Méd. vét., 1971, 147 (9) : 967-978.

5. TADJEBAKHCHE (H.) et GATEL (A.). Etude épizootologique d'un important foyer d'avortements causés par $S$. abortus ovis en Khorasan Iran. $40^{\circ}$ session générale du Comité de l'O.I.E. Rapport n' III. 1972.

6. TADJEBAKHCHE (H.) et GATEL (A.). Incidence sérologique des anticorps anti-Salmonella abortus ovis chez les animaux domestiques en Iran. Rec. Méd. vét., 1972, 148 (9): 1027-1030.

7. TADJEBAKHCHE (H.), NADALIAN (M.) et HOSSEINIOUN (M.). Infection expérimentale par Salmonella abortus ovis de brebis vaccinées et non vaccinées. Rec. Méd. vét. (à paraître).

8. TADJEBAKHCHE (H.), HOSSEINIOUN (M.) et NADALIAN (M.). Infection expérimentale due à Salmonella abortus ovis chez la chèvre. Rec. Méd. vét. (à paraître).

9. HUGH-JONES (M. E.). Salmonellosis and VIDA. Vet. Rec., 1969, 87 : 275-276. 